\title{
PARADOX AND ARGUMENTATION \\ FROM RHETORIC TO THE REFINEMENT OF MATHEMATICS
}

SEBASTIÀ SERRANO

Paradoxes - and the problem they present for logic - can be traced as a subject for reflection from the Sophists to contemporary language philosophers and mathematicians, visiting Aristotle, Abel and Russell along the way, during which time rhetorical algebra transitioned into syncopated algebra and then to symbolic algebra. The paradox can be seen as an obstacle to aseptic reasoning, but it can also act as a compelling stimulus for imagination and the practice of argumentation or persuasion, a rhetorical tool that has encouraged rigorous thinking throughout history, in an attempt to avoid "concealed» lies in all kinds of discourses. It is, therefore, a challenge that inspires creativity within a culture indebted to the rhetorical tradition.

Keywords: rhetoric, logic, argumentation, paradox, self-reference.

\section{PARADOXES IN CLASSICAL RHETORIC}

Twenty-five centuries ago in Greece, an absolutely transcendent event boosted the development of culture and, therefore, our species. Decisive events, including a favourable socio-political and economic context related to the advent of democracy, brought philosophical thinking about reality, the world and self - the same thing really - to language. We should remember that all previous philosophy, from Tales to Parmenides, had focused on the world and nature and aimed to understand natural phenomena. However, sophists placed language at the centre of their thinking. They studied discursive and communicative strategies in order to instruct in the art of communication. From that time on, a large proportion of Greek philosophy was the philosophy of language, whether in the form of rhetoric, logic, poetics or grammar (Serrano, 1996; Vega Reñón \& Olmos González, 2011). Plato and Aristotle are its synthesizers.

With the advent of democracy, in the Greek tradition, we find an interest in and a taste for argumentation, dialectics and discourses constructed with the aim of being persuasive. In time, it was recognised that the ability to persuade granted unquestionable power: the power of having words without objects, of affecting people through words, through discourse. In such a society, where certain classes had agreed to democratic life, argumentation and public debate were important and common in the Agora and in the courts of justice. A good education was fundamental. One of the most common discursive strategies used to succeed in debates was, for instance, using your opponent's premises to reach an impossibility as a logical consequence.

Aristotle named Zeno of Elea and Socrates as the masters of this strategy. At that time, when argumentation was principal, several fallacies started to appear that forced people to reflect upon the general criteria that should characterise good reasoning. For instance, a debate along the lines of «This dog is a father. This dog belongs to its owner. Therefore, this dog is the father of his owner». Clearly, this is a deceptive reasoning process, although it follows a strictly correct reasoning structure. Another example of this structure is «this object is a box, this object is blue, so this object is a blue box». These examples, selected from important debates of the time, were the subject 
of reflection for Aristotle in his research on the fundamental laws of the art of good reasoning. In addition, Aristotle also reflected upon the arguments of geometrists attempting to discover the art of deduction, of demonstration, in order to overcome the long crisis related to irrational and infinitesimal numbers. Zeno's paradox, with Achilles and the tortoise, was the focus of many debates. The story goes like this: «Swift-footed» Achilles races against a tortoise and gives the animal a head start. When the warrior reaches the point where the tortoise was, it has already walked a little bit farther, so Achilles needs to run a little more to cover that distance, but while he does that, the turtle will have walked a bit more, and so on. Therefore, from a mathematical point of view - and against empirical evidence - the swift-footed runner would never cover the distance that separates him from the slow animal.

Certainly, reflection on the validity of argumentation must have become almost obsessive, as it was the axial point for both geometrical and rhetorical discourse, the latter being, to a certain degree, the mother of all discourses. This is the reason for Aristotle's interest in developing a kind of «taxonomy» of argumentation, that is, a systematic classification that he called syllogistic, with different types of syllogisms that opposed the rhetorical syllogism. The framing of syllogistic modes did not have the flexibility required for most of the arguments used in geometry or in the Agora. That is why some schools, such as Stoics or Megarians, formulated alternative non-syllogistic logical structures that allowed them to operate with more flexibility and fluidity. A good example were the two inference rules called modus ponens - that is, «if $p$ then $q$; we assert $p$, therefore $q »-$ and modus tollens - «if $p$, then $q$; so no $q$, then no $p$ ».

Of course, since Plato, the validity of an argument had to be linked to the concept of truth, and that led to the proliferation of a fascinating linguistic, logical and mathematical phenomenon, those famous paradoxes that sprang like mushrooms after rain on the field of discourse. In this way, the Greeks formulated some of the enigmas and logical puzzles that have tortured mathematicians, philosophers and rhetorical experts to this day. Sophists specialised in stunning and confusing their opponents during debates - often as purely rhetorical exercises in the arena of public speaking -, although most of them just wanted to stand out in the swampy discourse of dialectical tricks.

There was a group of disturbing and perplexing enigmas that stubbornly resisted all sorts of inquiries. Most originate from what we know as «vicious circle fallacies», caused by neglecting the fundamental principle that implies that the whole of a given totality cannot be part of the totality. For example, the wellknown barber paradox has come to us from medieval logic. This states that the town's barber shaves everyone

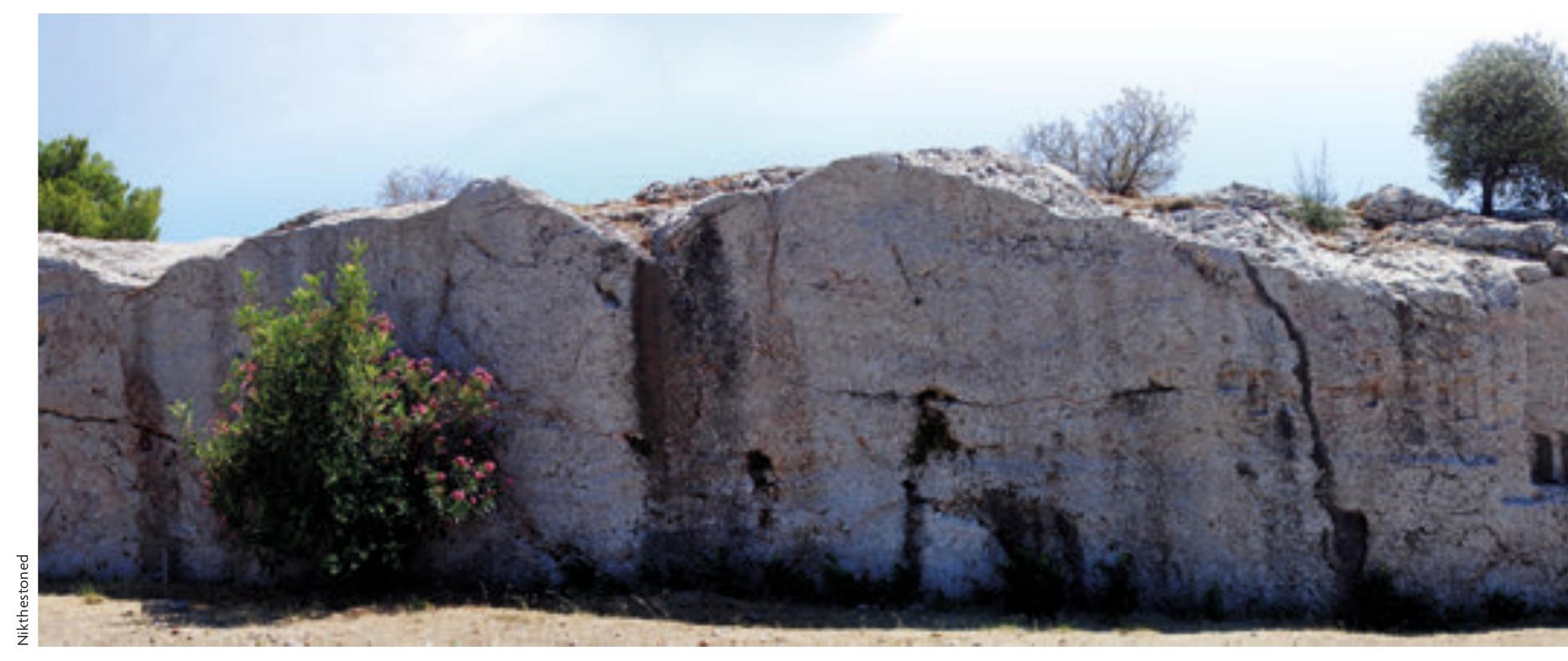


except those who shave themselves. So, does the barber need to shave himself? If he does, he is shaving someone who shaves himself and breaks his own rule. If he does not, he will not be shaven and will break the rule because he is not shaving someone who does not shave himself.

Another substantial part of these enigmas is connected to the tradition of the liar's paradox, also known as the paradox created by Epimenides of Knossos, which immortalised the statement: «All Cretans are liars», with the variations «I am lying» or «This sentence is false». Note that it is a statement that drastically contradicts the universally accepted dichotomy between true and false statements. If I say «What I'm saying is false», what I say cannot be true, because then it would be false. And it cannot be false, because then it would be true. It is neither true nor false, or it is both. Or better still, it is true if it is false, and it is false if it is true. The discovery of this circularity, almost distressing, contradictory and inconceivable, does not have to stop language and social life as result of a fascinating collision. A similar thing can occur when we discuss topics such as «natural selection» in biology. Thus, natural selection selects the fittest. But, who is the fittest? The one that gets selected by natural selection... However, disappointment, desolation and even grief - I am thinking of the letter Gottlob Frege received from Bertrand Russell - starts when one tries to construct a continuous logical structure into which mathematics should fit.

The liar's paradox circulates through every school of logic from the Middle Ages to the modern world. I personally like the version about the hunted hunters. It

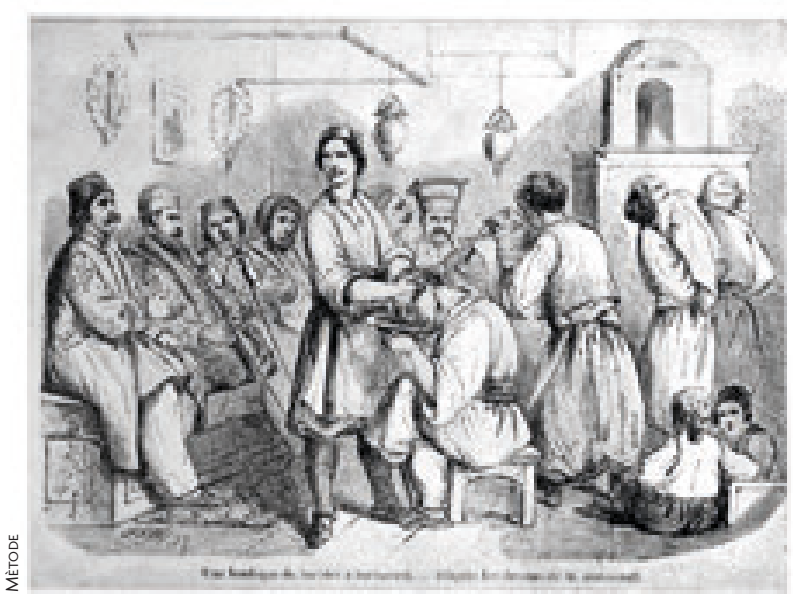

Most perplexing riddles originate from what we know as «vicious circle fallacies». For example, the well-known barber paradox, according to which the town's barber shaves everyone except those who shave themselves. So, should he shave himself or not? If he does, he is shaving someone who shaves himself and breaks his own rule. If he does not, he will not be shaven and will break the rule because he is not shaving someone who does not shave himself. In the picture, an engraving of a barber's shop in Bucharest circa 1842 by Charles Doussault (1814-1880).

With the advent of democracy, in the Greek tradition, we find an interest and a taste for argumentation, dialectics and discourses constructed with the aim of being persuasive. Below, a picture of the Pnyx hill, west of the Acropolis of Athens, where Athenians met to discuss the affairs of the city.

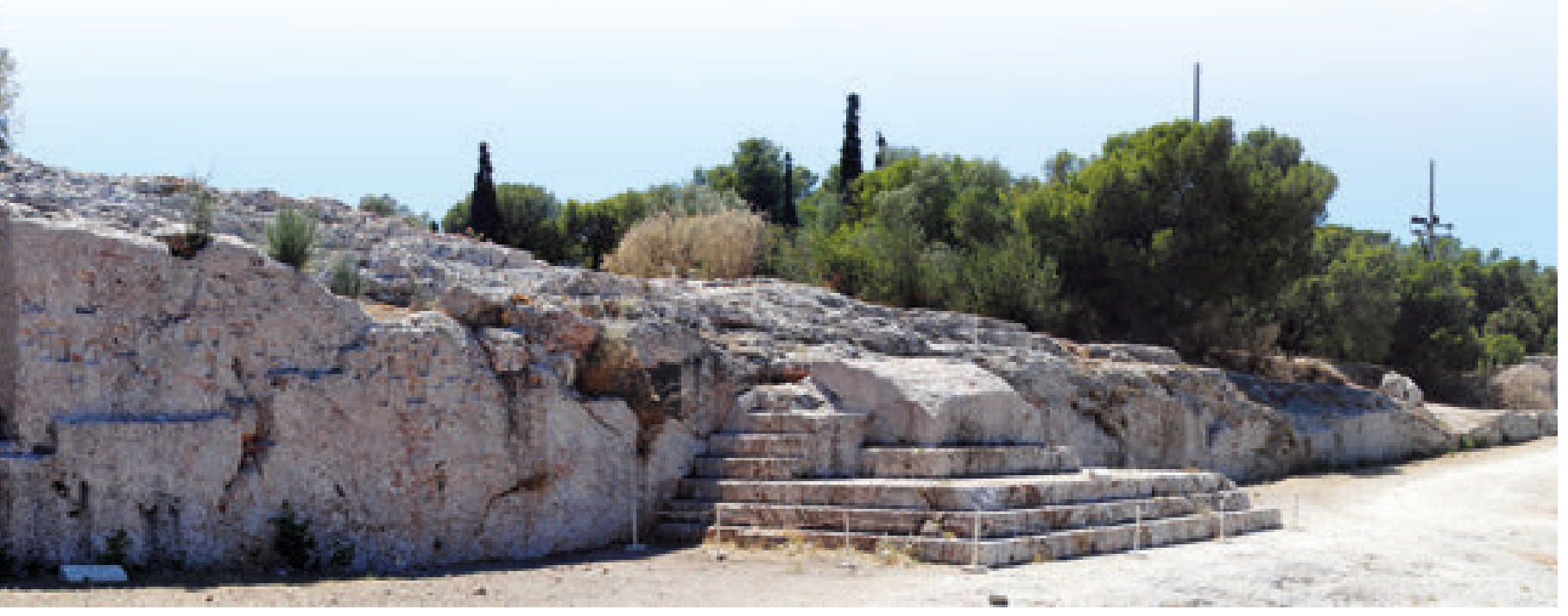


can be summed up more or less as follows: hunting in the prince's lands was punishable by death. However, it occurred to him to decree that «anyone who was caught hunting would be offered the privilege to choose if he would be hanged or beheaded. The accused would utter a sentence; if it were false, he would be hanged, if it were true, he would be beheaded. A very spirited and logical boy took advantage of this prerogative when he stated: «You shall hang me». They had not taken this dilemma into account, and he blurted out his elegant reasoning: «If you hang me you will break the prince's law, as I should be beheaded for telling the truth, and if you behead me you will also break the law, because if you do, what I have just said is false, so I should be hanged». In my book La Paradoxa ("The Paradox") (Serrano, 1985), I collect - and construct - many examples of the liar's paradox. Incidentally, we can find a variant of it in Don Quixote. Sancho Panza is faced with it when he is the governor of the island of Barataria and has to decide whether or not he should condemn a prisoner who poses a similar paradox. He solves it in a practical way, applying the principle of favouring the prisoner in a case of doubt.

\section{THE DEVELOPMENT OF} ALGEBRA

\section{An enigmatic epitaph is written}

on the tomb guarding the ashes of the mathematician Diophantus, who lived in Alexandria during the third century. It informs us that his childhood amounted to a sixth of his life, that his beard grew for one twelfth more, and «the flame of marriage was burning» for an additional one seventh. Five years later his son was born, he lived for only half of his father's life, who lived for four more years after the death of the child, in a grief only alleviated by «research in the art of numbers». Today, it is very easy to solve this riddle. If $x$ is the age at which Diophantus died, then:

$$
\frac{x}{6}+\frac{x}{12}+\frac{x}{7}+5+\frac{x}{2}+4=x
$$

Therefore, the great Diophantus lived for 84 years.

The study of how to formulate mathematical statements, the process of symbolisation and formalisation, represents one of the most impressive methodological and epistemological efforts of the human mind, which helps us to generate the most sophisticated formalisms opening the doors to
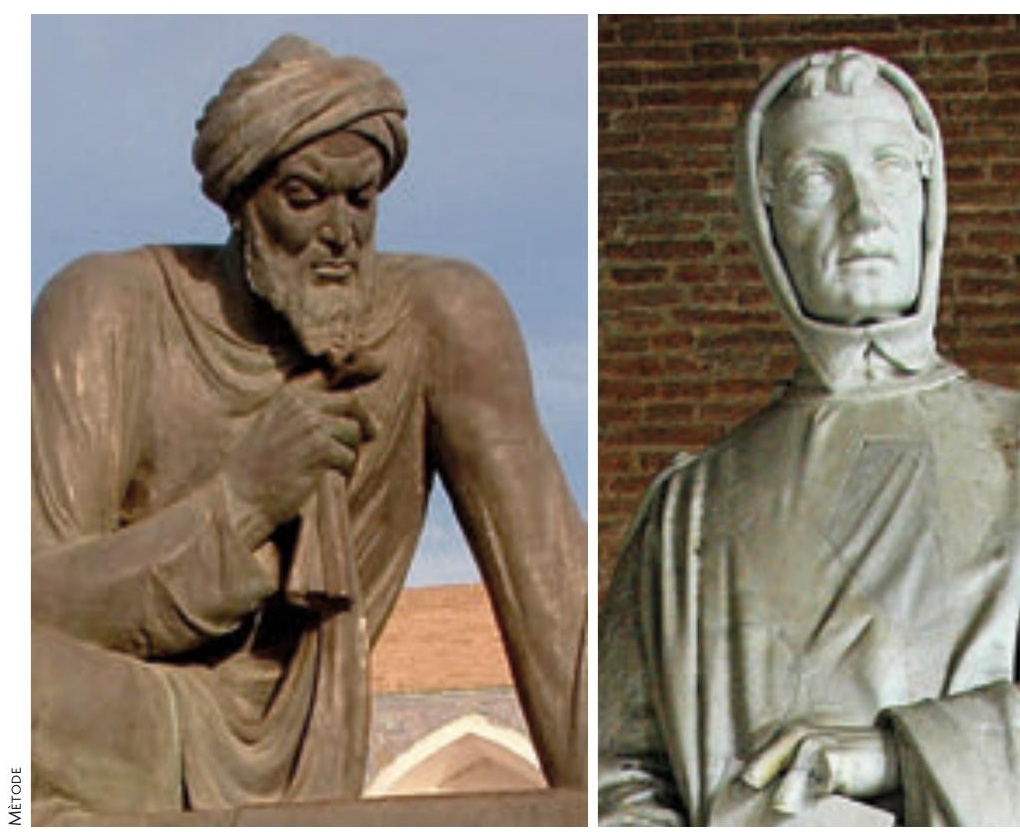

artificial intelligence. Today, as we saw in the simple equation about Diophantus's age, the solution is almost immediate. However, the problem of notation of Greek geometrical or arithmetical formulations was already considerable. Many of the modern formulations are the result of transcribing the Greek ones, originally presented in different ways via ordinary language, using words with a broad semantic spectrum. In fact, good notations are absent until the work of mathematician François Viète is published in the late sixteenth century; and the algebraic formulation we recognise is not commonplace until the middle of the seventeenth century, and even then, it is reminiscent of ordinary language. This has led algebra scholars to establish a distinction, in stages, between rhetorical algebra, syncopated algebra and symbolic algebra.

The arithmetic of Diophantus, and a good portion of Greek mathematics, reappears in the ninth century translated and assimilated into and discussed in Arabic. The first algebraic treatise by Al-Khwarizmi also appeared in the early ninth century. For a long time, algebra was considered the science of equations. All of these Arabic treatises, translations and reviews were brought to the Western world in the early seventeenth century by the mathematician Fibonacci. Fibonacci made a case for the Hindu-Arabic numeral system, which we still use today. He taught number 

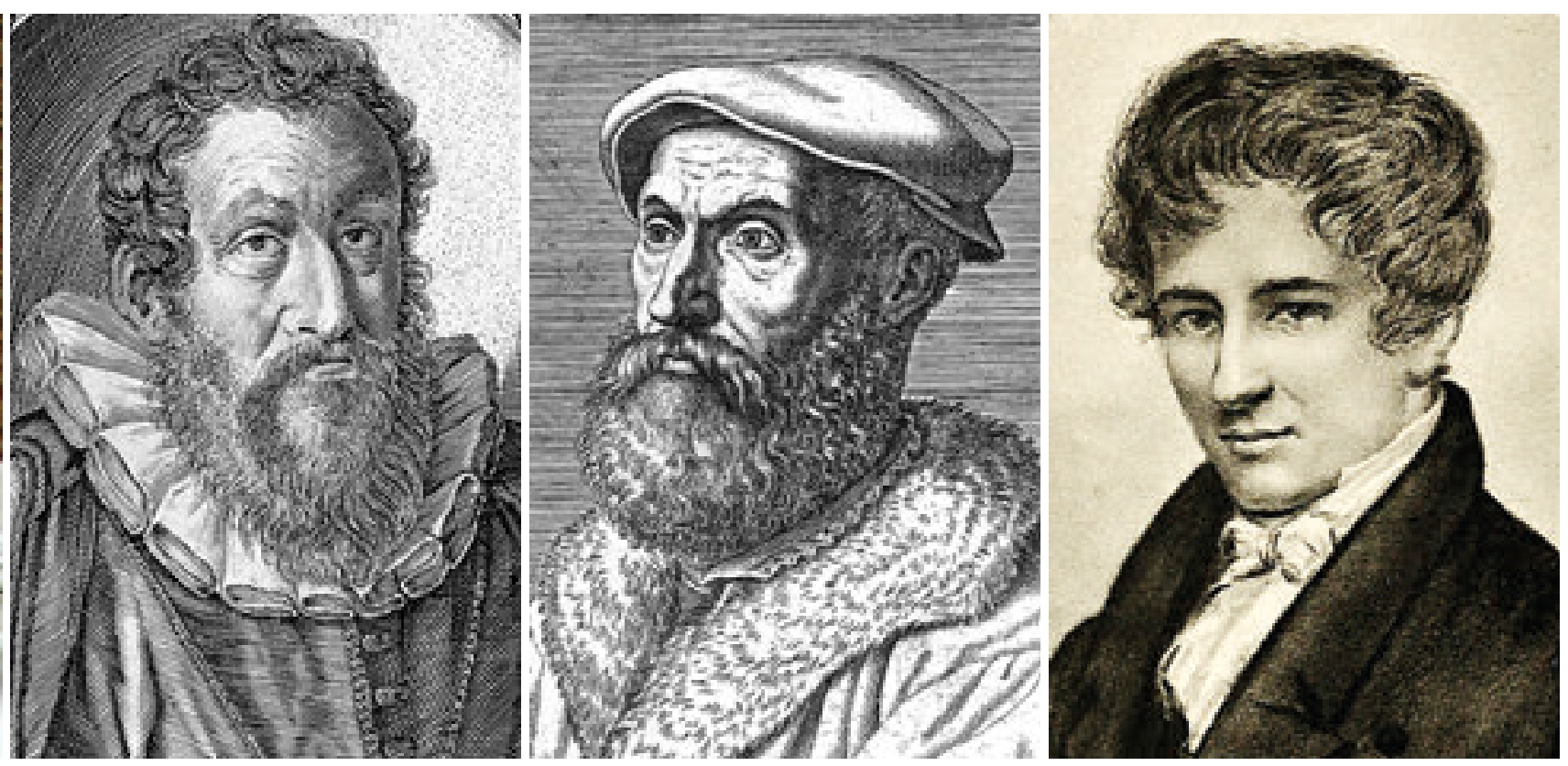

Many of the modern formulations in algebra and arithmetic are the result of transcribing the Greek ones, originally presented in different ways via ordinary language, using words with a broad semantic spectrum. In fact, the algebraic formulation we recognise does not become commonplace until the middle of the seventeenth century. Left to right, mathematicians Al-Khwarizmi, Fibonacci, Gerolamo Cardamo, Niccolò Fontana and Niels Henrik Abel.

literacy and informed about the rules of calculus, operation between numbers, integers and fractions, the extraction of square roots and, especially, methods and algorithms to solve first and second degree equations. He did so with an exquisite model for the theory or argumentation, which is, after all - as Aristotle claimed - the tabernacle of rhetoric.

Once algebra is established, the race begins to solve cubic equations, and then quartic ones. Solving an equation meant determining the value of the variable using calculus - an algorithm - that affected only the coefficients that accompanied the variable in their different degrees. In the sixteenth century, Gerolamo Cardano and Niccolò Fontana (also known as «Tartaglia», which means "stutterer") found the solution for the cubic equation $a x^{3}+b x^{2}+c x+\mathrm{d}=0$. One of Cardano's disciples, Lodovico Ferrari, solved quartic equations at the end of the century. The enormous efforts of the most famous algebra scholars encountered a great obstacle, a critical point, in solving the quintic equation, until, in 1826, mathematician Niels Henrik Abel managed to prove the impossibility of solving it - or any further degree equations - by the usual means. A complete frustration for the great mathematical brains.

However, Niels Henrik Abel introduced a different approach to an algebra problem. For the first time, he asked: What is solving a problem? He designed a programme on procedures to solve a problem and how to formulate these procedures. It was a true reflection on the discourse of problem solving and how we could create a standard - in our language - for these procedures and algorithms, how we could formalise them and, even, automatise them. This shows another side to the theory of demonstration and the theory of argumentation. Logic and the core of rhetoric configured simultaneously.

\section{CONTEMPORARY LOGIC AND MATHEMATICS}

Around 1885, the German mathematician Georg Cantor formulated a compelling and powerful theory that would greatly challenge intuition - the famous set theory. The impact on the field of logic and mathematics was huge. Many thought it could become a great theory to unify the different branches 
of mathematics. Soon, as prominent a logician as Frege ventured into the quest for a foundation for arithmetic, based on set theory, a challenge which he tackled for a long time. When he finished, he sent the result - the foundation of arithmetic - to some of the most qualified mathematicians of the time. He sent it to Russell, who answered with a letter that Frege would not wish upon his worst enemy. Indeed, Russell detected a number of paradoxes that appeared in Frege's system and weakened the whole theory.

Russell reminds him of a paradox - known as Russell's paradox -, which in Kurt Grelling's formulation goes approximately as follows: we will divide all the predicates into two categories (sets), those which can be their own predicate, such as polysyllabic, which is, indeed, a polysyllabic word, or English, which is, indeed, an English word (because polysyllabic has several syllables and English is a lexical unit that can be found in an English dictionary). We call these predicates and the set containing them autological. On the other hand, those that cannot be their own predicate will be heterological. This is the case with monosyllabic or Spanish, because the first word is not a monosyllable and the second word is not in Spanish. The big question concerns the heterological predicate. What is it, heterological or autological? Which set does it belong to? It can only fit one of them. But, if it is autological, then it is heterological, and if it is heterological, then it is autological. In other words, it can only be autological when it is heterological, and vice versa. And it can only belong to the autological set if it does not. «Oh, my God!», Frege would exclaim. Thus, the Aristotelian principle of the excluded middle was broken (it is alive or dead: A is $\mathrm{B}$ or not $\mathrm{B}$, there is no intermediate possibilities). This fact shook the foundation of the theory.

Self-reference is the root of all evil, the oxygen that fuels the flame. The paradox lies in the fact that the formulation affects the formulation. Saying «this statement is false» is metalanguage; language about language, so Russell's «paradoxical» set is nothing more than the result of neglecting the differentiation between a set and a metaset, a set of sets. The problem was the mixture of levels, of types, as Russell would say. The solution lies in having sufficiently demarcated boundaries and types, differentiating clearly between levels of abstraction. So the rules of Bertrand Russell and Alfred North Whitehead's monumental Principia
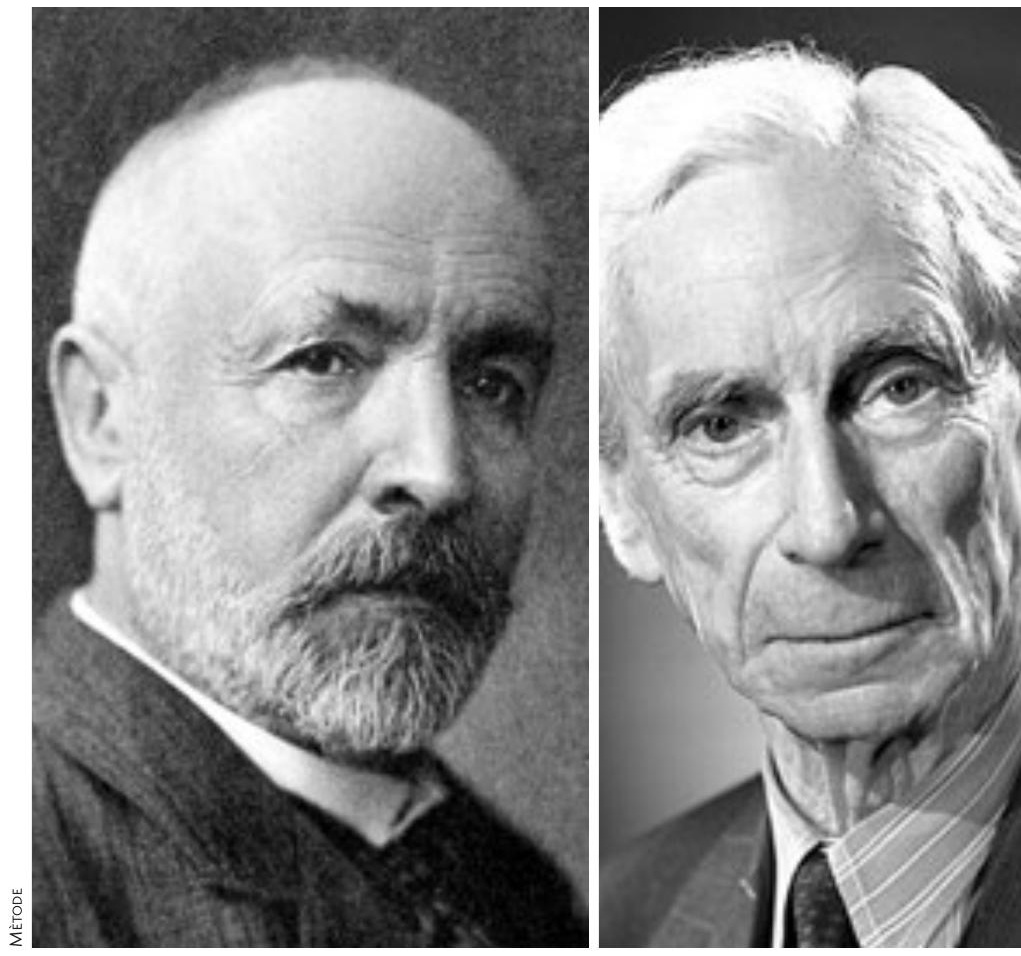

mathematica do not allow the closed system of reversible feedback, which was like a dog chasing its tail and opening the door to self-contradiction. In fact, they created a firewall that prevented the vice of circularity in reasoning. Reminiscences of the liar's paradox finally disappeared. It appeared that everything was perfect in the world of logic.

During the first decade of the twentieth century, Hilbert worried about the perceptible crisis at the core of mathematics due to paradoxes, so he urged mathematicians to organise Cantor's set theory on a solid axiomatic foundation - like Russell - consisting of a limited number of postulates. This marked an important shift towards an emphasis on mathematical abstraction. Mathematicians increasingly moved further away from «intuitive content», corresponding in this case to surfaces or lines towards a situation where mathematical concepts are free from their direct content and are simply defined axiomatically within a context, a frame, a theory.

The age of formalism had arrived and they could refer to numbers, straight lines or clouds or broken hearts. This formalism promoted the use of mathematics to solve problems that had been 

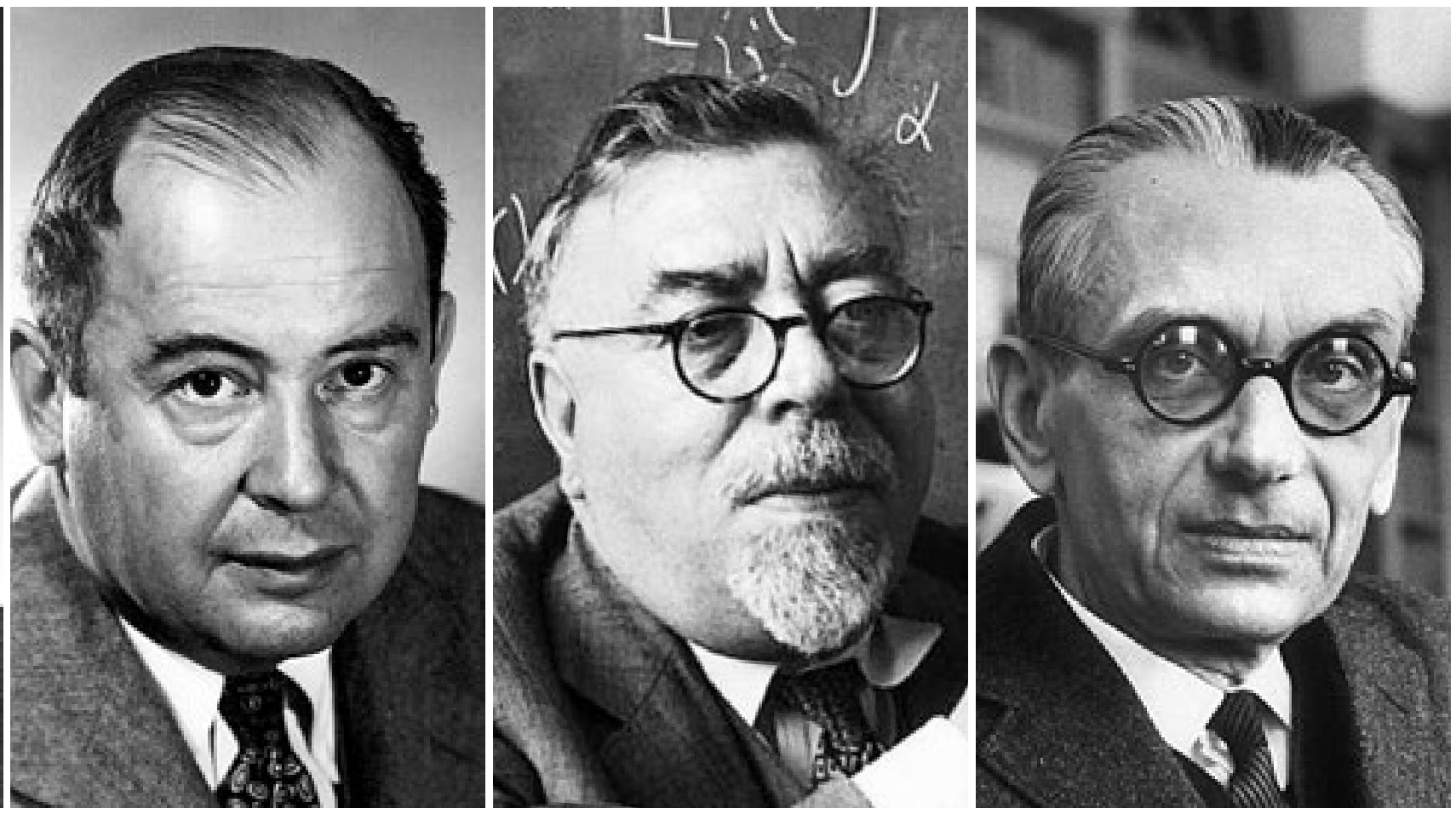

From left to right, pictures of Georg Cantor, Bertrand Russell, John Von Neumann, Norbert Wiener and Kurt Gödel. The work of these authors, among others, was crucial for the development of contemporary logic and mathematics.

considered impossible to submit to highly formalised treatment. David Hilbert, André Weil and subsequently John Von Neumann, had considerable success in extending the axiomatic approach to a number of new problems: perhaps the most emblematic in the new physics, such as quantum mechanics, but also logic or the new game theory. Mathematics had become more than a profession, it was a wonderfully dynamic adventure. With Alan Turing, Claude Shannon or Norbert Wiener, a fantastic idea started to crystallise: that the human mind could achieve anything with mathematical ideas. We should find this intellectually fascinating and aesthetically pleasing. Yes, and many advances in mathematics were made thanks to the observation of unsuspected relationships between objects that seemed intractable and other objects that mathematicians had already mastered.

However, at a time of great mathematical optimism, Kurt Gödel proved his incompleteness theorem and spoiled Hilbert and Russell's optimism (Hofstadter, 1979). Paradoxes were alive and well! With a flawless logical exercise, the most brilliant, difficult and surprising in modern logic, Gödel's showed that the formal axiomatic method that had served mathematics for so long and so well, also had some limitations. In a way, he told us that formal deduction had, in part, refuted itself. However, as Ernest Nagel and James R.
Newman communicated in their famous work Gödel's Proof (Nagel \& Newman, 1970), this was not a reason to despair, quite the contrary, in fact, it justified «a renewed appreciation of the powers of creative reason».

We believe that paradoxes, which started as a thorn in the side of good reasoning, of valid argumentation in the Agora and in primitive logical and mathematical discourse, have become a reference point to support the discourse of rigour and clarity, where «concealed information» that can cause a contradiction has no place. However, the butterfly of paradox continues to fly within the universe of discourse, as one of the most successful examples of creativity in cultural spaces. (-)

\section{REFERENCES}

Hofstadter, D. R. (1979). Gödel, Escher, Bach: An eternal golden brain. New York: Basic Books.

Nagel, E., \& Newman, J. R. (1970). El teorema de Gödel. Madrid: Tecnos. Serrano, S. (1985). La paradoxa. Barcelona: Planeta.

Serrano, S. (1996). Comunicació, llenguatge i societat. Barcelona: Edicions 62. Vega Reñón, L., \& Olmos González, P. (Eds.). (2011). Compendio de lógica, argumentación y retórica. Madrid: Trotta.

Sebastià Serrano. Full Professor Emeritus of Linguistics at the University of Barcelona (Spain). He published several studies on linguistics, semiotics and communication theory. He received the St. George's Cross Award from the Catalan government in 2003. His first book, Elementos de lingüística matemática ("Elements of mathematical linguistics", Anagrama, 1975) won the Anagrama Essay Award. Two of his most recent books are La fiesta de los sentidos ("The festival of senses", Now Books, 2009) and Del amor, la mentira y la persuasión ("Of love, lies and persuasion", Destino, 2013). 